\title{
Full Validation of a New Formula Estimating the Smoking Economic Burden by Morbidity
}

\author{
FéFernández Hernández* and Efraín Sánchez González \\ Faculty of Medical Science "10 de Octubre", at University of Medical Science of Havana. Havana, Cuba \\ *Corresponding author: FéFernández Hernández, Faculty of Medical Science "10 de Octubre”, at University of Medical \\ Science of Havana. Havana, Cuba
}

\section{ARTICLE INFO}

Received: 慧 October 04, 2021

Published: 慧 October 19, 2021

Citation: FéFernández Hernández, Efraín Sánchez González. Full Validation of a New Formula Estimating the Smoking Economic Burden by Morbidity. Biomed J Sci \& Tech Res 39(3)-2021. BJSTR. MS.ID.006302.

Keywords: Estimation; Smoking Economic Burden; Morbidity

\begin{abstract}
Introduction: In the Health Economy research context usually researches are assuming that the probability of the morbidity attributable to smoking is equal to the probability of the health spend attributable to smoking. Also is attributed the whole health spend because of active smokers to smoking. To solve this limitation, the authors suggested a new rate to measure the smoking economic burden by morbidity.

Objective: To evaluate the feasibility from a new rate to measure the smoking economic burden by morbidity.

Methods: Was made a bibliographic research to describe the estimation process from the smoking economic burden by morbidity. Were utilized as theoretical method the analysis and synthesis, the comparative and the systematization. As empiric methods were used the Principle of Multiplication and the bibliographic research.
\end{abstract}

Results: The rate designed solves the limitation identified during the research about the estimation of the smoking economic burden by morbidity.

Conclusion: The new rate will provide a better estimation from the smoking economic burden by morbidity. It application will may identify the role of active smokers and passive smokers in the formation of the smoking economic burden. However, it application must be agree to the supposes identified.

\section{Introduction}

Smoking is a significant health market weakness close related to tobacco consumption intensity. The smoking impact over the health finance management carries to big fiscal spends agree to the tobacco consumption intensity too [1]. In the Health Economy context is usually used the illness burden attributable to smoking (morbidity close related to smoking probability's) as similar to the smoking economic burden by morbidity (probability to health spend because of smoking) [2]. This limitation is given because there isn't a single generalized form estimating the smoking economic burden by morbidity because this risk factor is researched as other risk factor without take account the self-particular characteristic from smoking. Then, the precise measurement from this rate is a significant present necessity for epidemiologic researches and health Budget administration too [3]. Smoking is given by the tobacco consumption [4]. Smoking impact over the Public Health mean san opportunity cost because of financial pressure to the health financial administration attributable to tobacco consumption [5]. People agree to tobacco consumption support that smoke is a personal and single decision. However, this argument don't take account the smoker dependence to tobacco consumption because of nicotine. Also make reference to the effective employment because of the tobacco economy. Nevertheless, this argument don't consider the labor productivity lose attributable to smoking given by labor time lose smoking and smoker earlier death before retire 
age [6]. Also is supported that earlier smoker death carries to fiscal save because of reduction in retirement payments. However, this argument don't take account all social costs attributable to smoking before the smoker death [7].

Acknowledge the whole smoking economic impact over the health financial administration is very important. As consequence is important a precise measurement from this economic impact to design and apply effective policies or the smoking control [8,9].WHO is agree increasing tobacco price by tax. This economic policy must provide a context where fiscal income would increase and tobacco consumption would reduce because of the general behavior from these economic goods as ordinaries and necessaries goods [10]. Thus is evidenced the real necessity from the precise estimation from the smoking economic burden for the Public Health and the whole society too [11]. In Cuba, fiscal income related to tobacco consumption, the economic heavy from the tobacco industry over the external trade and the social and cultural conditions close related to tobacco consumption don't make easy the effective smoking control [12]. Cuba had developed several researches describing the relation between tobacco consumption, Price and other economic variables. However, Cuba hasn't an actualized cost - benefit relation quantified to support an economic policy for an effective reduction from the tobacco consumption. This situation is given by the unknowledge from the smoking economic burden measurement's [13]. Also had been researched the use from the tributary policy for the smoking control, showing the fesiability from this policy type to reduce the tobacco consumption. Nevertheless, anyone from these researches shows the whole smoking economic burden over the Public Health $[14,15]$. From the ten main death causes in Cuba seven are close related to tobacco consumption. All of them are no - communicable illnesses [16]. Patients attention because of these morbidity and mortality causes are mainly present in health institutions with middle or high especialization, carring to more expensive health services because of smoking [17].

Cuban's goverment organizations had established several measures for the smoking control. However, the empiric evidence shows that those measures aren't applied wholy [18].

By other side, the salarial measures adopted since had contributed to raise the net salary. For example, in 2010 the middle salary in Cuba was $\$ 448.00$. In 2018 was $\$ 777.00$. This increasing represent more than $9 \%$ growing annualy. However, since 1990's until 2019 the trade minor price from tobacco was the same, only $\$ 7.00$ the box of 20 units. This price represent less than $\$ 0.30$ USD per box. This position had done more available the tobacco products carring to increase the effective demand of health services attributables to smoking. However, the unknow from the smoking economic burden by morbidity don't may make a detailled valuation from the smoking impact over the health services administration [19]. Estimating the smoking economic impact are used mainly two ways. One is using the standart cost agree to the illness protocol. This method is used in limited context as health institution, for example, because of the unavailable generalization use for big populational research, for example, esstimating the smoking economc impact over the health services in a whole economy. At same time, this situation conditiones the effective capability from fiscal authorities for the smoking control [20]. The second way is agree to the economic burden rate. This method looks for determine the expected relative value from the Public Health spend attributable to smoking. This method is largely used in populational researches and is the main supporting the designing and application of public policies for the smoking control. This is the main method analyzed in this research.

\section{Smoking Economic Burden by Morbidity Agree to the Illness Burden}

The illness burden is an epidemiologic concept to measure the morbidity impacto ver the researched population. In relative terms is equivaent to the probability from the selected morbidity in the reearched population. In the analysis from the illness burden is included the analysis from the economic burden from the morbidity cause or risk factor researched. This ter mis equivalent to the probability from the cost attributable to the morbidity cause or risk factor researched [21]. Respect to smoking researching as risk factor, the morbidity attributable is a necessary condition but not sufficient determining the smoking economic burden by morbidity. Since the economic point of view, the illness burden attributable to smoking determines the potential demand of health services because of smoking while the economic burden by morbidity determines the effective demand of health services attributable to smoking [22]. Much researches uses the rate for illness burden attributable to smoking as the rate for the economic burden attributable to smoking by morbidity. This practice carries to a methodologic mistake and may make less trustable the researches results. Especifically this position is assumed when researches uses the economic burden because of active smokers as similar of the smoking economic burden by morbidity. Nevertheless, not all health spend because of active smokers is attributable to smoking and from no smokers health spend a portion is attributable to smoking because of passive smokers [22]. Then, the smoking economic burden by morbidity because of active smokers is always less than the illness burden attributable to smoking. Using both rate as similar carries to over value the true smoking economic impact over the health services.

As example of that is research from 2016 in Latin America. In this case authors used the rate from the economic burden by morbidity in a way wich interpretation suggests that illness burden attributable to smoking because of active smokers is equal 
to the whole smoking economic burden by morbidity [23]. Other authors as Ariel Barchad [24], Isaranuwatchai [25], Lightwood y Glantz [26], Sung Max [27] had developed similar researches with similar procedure too. This condition shows the necessity to remake the rate estimating the smoking economic burden by morbidity because of active smokers. In Cuba had been developed several researches related to the smoking economic impact. Much from these researches compare the health spends because of active smokers and no active smokers assuming that the difference between then is attributable to smoking. By this way is assumed the same position previosly analyzed where the health spend by active smokers is used as equal to the health spends attributable to smoking [28]. These researches are suppousing that smoking dimension depend only from the active smoker existence witout consider the relation between the tobacco consumption intensity and the added affect from smoking in the morbidity attributable and the economic burden by morbidity too [28].

By other side, in the analyze from the smoking economic burden by morbidity is usually excluded the passive smokers. This condition makes that the smoking economic burden by morbidity isn't showed wholy. In this case is important appoint that passive smoking is determined by active smoking because the tobacco active consumption determines the active smoking which determines the passive smoking. Then, the tobacco active consumption and the smoker's number are main variables explaining the smoking economic burden by morbidity and not only the smoker's number [22]. Passive smoking plays an important role estimating the smoking economic burden by morbidity and particularly in the cost - benefit relation. Passive smokers induce to health spend attributable to smoking agree to the economic burden attributable to smoking because of active smokers. Also, passive smokers don't carry to fiscal income because they don't by tobacco. However, passive smokers spend attributable to smoking may be very significant too [29]. Abstracting, since the economic point of view the main limitation identified estimating the smoking economic burden by morbidity is given by attributating the whole smoking economic burden by morbidity to actie smokers. That's why a precise estimation from the smoking economic burden by morbidity demand two main modification:

1. Remake the rate for the smoking economic burden by morbidity because of active smokers.

2. Include in the analyze the passive smokers.

To answer these limitations Fé Fernández Hernández and Efraín Sánchez González introduced new conceptions that carried to propouse significant transformations estimating the smoking economic burden by morbidity agree to the Medical Journal of Pinar del Río [29]. Nevertheless, it is necessary to valorate the designed rate to measure the smoking economic burden by morbidity. This is the main objective from this research.

\section{Methods}

Was made a bibliographic research to describe the estimation process from the smoking economic burden by morbidity. Were utilized as theoretical method the analysis and synthesis, the comparative and the systematization. As empiric methods were used the Principle of Multiplication and the bibliographic research

\section{Results}

The economic burden attributable to someone risk factor is determined by the happening of three independient successes at same time: the existence of some person affected by the researched risk factor, the existence of the morbidity related to the researched risk factor and the effective demand of health services attributable to the researched risk factor [22]. Each one from these successes has a probability associated. Agree to the Multiplication Principle, if someone success $\mathrm{A}$ is determined by the happening of several independient successes at same time, the probability associated to $A$ is equal to the product of the probabilities from all successes determining the A happening $[30,31]$.

\section{The Smoking Economic Burden Over the Public Health}

All tobacco consumption damages the human health. Then, the illness burden by smoking born since the minimun tobacco consumption. In the smoking economic burden by morbidity case's isn't thus because this rate is also determined by the effective demand of health services attributable to smoking. Given that the potential demand is higher than the effective demand, then, the effective demand of health services attributable to smoking is less than the potential demand of health services attributable to the same risk factor. In epidemiologic terms means that the illness burden attributable to smoking is higher than the economic burden attributable to smoking by morbidity all rate measured in reative terms as Fé Fernández Hernández and Efraín Sánchez González suggested. However, there is a direct proportional relation between the effective demand of health servics attributable to smoking and the tobacco consumption over the minimum tobacco consumption determining the existence of the effective demand of health services attributable to smoking. This means that higher tobacco consumption over that minimun consumption means higher effective demand of health services attributable to smoking. Also means that with the growing of tobacco consumption the difference between the illness burdens attributable to smoking and the smoking economic burden by morbidity will be closing.

The cited authors introduce two main concepts showed in following. 
1. Minimun economic consumption (mec): minimun tobacco consumption determining the effective demand of health services attributable to smoking.

2. Gross economic risk (ger): part from the illness burden by morbidity determined by the effective demand of health services attributable to smoking. It is equivalent to the probability of the effective demand of health services attributable to smoking.

Agree to authors, the mathematic fuction ger determined by the tobacco consumption (tc) has two parts

$$
\begin{aligned}
& \operatorname{Ger}(\mathrm{tc})=0 ; \mathrm{tc} \leq \mathrm{mec} \text { and } \\
& \operatorname{Ger}(\mathrm{tc})=1-\mathrm{mec} / \mathrm{tc} ; \mathrm{tc}>\operatorname{mec}[29]
\end{aligned}
$$

\section{Analizing Ger}

The tobacco consumption intensity and the morbidity attributable to smoking save a proportional relation with a dynamic in the same sense. As result, the effective demand of health services too because the close relaton between these variables [30].

In analytic terms should be equivalent to support that:

$$
\frac{d g e r}{d t c}=\frac{m e c}{t c^{2}}
$$

By other side the several impact from smoking over the morbidity at same time determine a desacelerated growing because the same patient only recieve a single health service at same time including when must afford several morbidity consequences attributable to smoking at same time. This phenomenon is more evident while tobacco consumption increases because of the growing in the morbidity attributable [30]. In analytic terms should be equivalent to support that:

$$
\frac{d^{2} g e r}{d t c^{2}}=\frac{-2 * m e c}{t c^{3}}
$$

By other side, it is evident that the smoking economic burden by morbidity is determined by the illness burden attributable to smoking and that's the main reason of why those rates is close related. However, the accumulative efect from smoking over morbidity suggest a faster growing from the smoking economic burden by morbidity agree to tobacco consumption intensity. This analysis close to the previous may support that:

$$
\lim _{t c \rightarrow \alpha}\left(1-\frac{m e c}{t c}\right)=1
$$

Abstracting, the rate suggested estimating the effective demand of health services attributable to smoking is trustable and contexted. Also is agree to the main economic and epidemiologic characteristics from smoking related to the estimation of the smoking economic burden by morbidity. As result, the smoking economic burden by morbidity because of active smoker must be calculated as the multiplication of the probability of the morbidity close related to smoking, the probability to has an active smoker and the probability of the effective demand of health services attributable to smoking given by ger. It is very important take account that exposition to tobacco smoke by smoking or passive exposition is a main variable to understand the smoking economic burden by morbidity behavior's [22]. That's why passive smoking needs be explicated by tobacco consumption and tobacco passive exposition at same time [20].

Null tobacco consumption means null smoking economic burden by morbidity because of passive smokers. This is because the smoking economic burden by morbidity because of passive smokers is determined by the smoking economic burden by morbidity because of active smokers agree to passive exposition rate. Then, assuming that

1) Morbidity causes attributable to smoking are the same for active and passive smokers, each one agree to self exposition to tobacco consumption,

2) The successes to have an active smoker, a passive smoker and a no smoker person are mutually excluding and complementaries at same time in the researched population

the whole suggested rate estimating the smoking economic burden by morbidity is aproppiate [20].

The new formula suggested estimating the smoking economic burden by morbidity also:

a. Acknowledges that only a part from the illness burden attributable to smoking has economic consequences agree to the effective demand of health services attributable to smoking:

b. Acknowledges the main role from the tobacco consumption intensity and the tobacco passive exposition estimating the smoking economic burden by morbidity, and;

c. Acknowledges the self responsibilities from active and passive smokers in the formation of the smoking economic burden by morbidity.

However, the most important from the new formula is given by identify the difference between the potential and the effective demand of health services both attributable to smoking. This suggestion solve the limitation identified previosly in this research. Nevertheless, ger rate isn't perfect because other rate with similar characteristic may obtain similar results but it easy useful suggest their utilization estimating the smoking economic burden by morbidity. The new formulation was partially utilized in the Cuban context limited to active smokers for 2019. The result showed that the $11.1 \%$ from the health spend in 2019 was attributable to active 
smoking. If in the cited research should be used the illness burden attributable to smoking as similar to the smoking economic burden by morbidity because of active smoker the rate value would be $16.4 \%$. This difference means an over valuation from the smoking economic burden by morbidity because of active smoker in $5.3 \%$, agree to the journal ECronicon Pulmonology and Respiratory Medicine [20]. Moreover the number result, the new formula solve the necessity to acknowledge and include the effective demand of health services attributable to smoking estimating the whole smoking economic burden by morbidity.

\section{Conclusion}

The new rate will provide a better estimation from the smoking economic burden by morbidity. Its application will may identify the role of active smokers and passive smokers in the formation of the smoking economic burden. However, its application must be agreed to the supposes identified.

\section{References}

1. Fernández Hernández F, Sánchez González E (2020) The Smoking Economic Burden in the National Institute on Oncology and Radiology from Cuba. Journal of Physical medical \& Rehabitation studies \& Report 2(2).

2. Fernández Hernández F, Sánchez González E (2021) Estimating the Smoking Economic Burden by Morbidity. TRIDHA Journal of Clinical Cases \& Reports 2022(S12).

3. Fernández Hernández F, Fernández Leal L, Sánchez González E, Zaldívar Pérez B (2021) The Touchable Smoking Social Costs. Journal of Clinical and Laboratory Research 2(3): 1-2.

4. Fernández Hernández F, Sánchez González E (2020) The Smoking Epidemiologic Control across the Primary Health Service. Asclepius Medical Research and Reviews 3(2): 1-3.

5. Fernández Hernández F, Sánchez González E (2021) The macro - social smoking control. Asclepius Medical Research and Reviews 4(1): 1-2.

6. Sánchez González E, Fernández Hernández F (2021) Brief Analysis about the Smoking Economic Benefits. Medical Journal of Clinical Trials \&Case 5(2).

7. Sánchez González E, Fernández Hernández F (2021) The absolute socioeconomic inequity attributable to smoking. Journal of Medical Care Research and Review. 4(5): 1-4.

8. Sánchez González E, Fernández Hernández F (2017) El rol de las autoridades fiscales en el control del tabaquismo. Rev. Ciencias Médicas 21(3): 62-67.

9. Fernández Hernández F, Sánchez González E (2021) El control del tabaquismo en el nuevo modelo económico cubano. Correo Científico Médico 25(3).

10. Selvaraj S, Srivastava S, Karan A (2015) Price elasticity of tobacco products among economic classes in India, 2011-2012. BMJ Open5(12): e008180.

11. Sánchez González E, Fernández Hernández F (2020) Brief Appointments about Fiscal Policy for the Smoking Control. Journal of Clinical Research and Report 2(5): 1-2.

12. Fernández Hernández F, Sánchez González E (2020) The Social and Economic Inequity from Smoking in Cuba. Annals of Medical \& Surgical
Case Report 2(2)

13. Fernández Hernández F, Sánchez González E (2020) Contributions Since the Health Economy Research to the Smoking Control in Cuba. Biomedical Journal of Scientific \& Technical Research 30(1): 2310223104.

14. Sánchez González E, Fernández Hernández F (2019) The smoking fiscal space in Cuba. Journal of Clinical and Medical Research 1(3): 1-5.

15. Sánchez González E, Fernández Hernández F (2018) La relación entre la política tributaria y el control del tabaquismo en Cuba. CCM 22(2): 238-249.

16. Ministerio de Salud Pública. Anuario Estadístico de Salud.

17. Sánchez González E, Fernández Hernández F (2021) Smoking, Health Market Equilibrium and Fiscal Policy. Journal of Clinical and Laboratory Research 3(3).

18. Red Cubana para el control del Tabaquismo. Regulaciones vigentes para el control del tabaquismo en Cuba.

19. (2019) ONEI. Anuario Estadístico de Cuba.

20. Fernández Hernández F, Sánchez González E (2021) Active smoking economic burden over the Cuban Public Health. EC Pulmonology and respiratory medicine $10(10)$.

21. Seuc Armando H, Domínguez Emma (2005) Acerca del cálculo de la carga de las enfermedades por morbilidad. Rev Cubana HigEpidemiol 43(3).

22. Fernández Hernández F, Sánchez González E (2019) Estimating the economic burden attributable to some risk factor. OAT Journal of Clinical Investigation and Studies 2: 1-2.

23. Pichón Riviere A, Bardach Ariel, Augustovski Federico, Alcaraz Andrea, Reynales-Shigematsu, et al. (2016) Impacto económico del tabaquismo en los sistemas de salud de América Latina: un estudio en siete países y su extrapolación a nivel regional. Revista Panamericana de Salud Pública 40(4): 213-221.

24. Bardach A (2016) Carga de enfermedad por tabaquismo e impacto potencial del incremento de precios de cigarrillos en el Perú. Revista Peruana de Medicina Experimental y Salud Pública 33: 651-661.

25. Isaranuwatchai W, De Oliveira C, Mittmann N, K (Bill) Evans W, Peter A, et al. (2019) Impact of smoking on health system costs among cancer patients in a retrospective cohort study in Ontario, Canada. BMJ Open $9(6)$

26. Lightwood J, Glantz SA (2013) The Effect of the California Tobacco Control Program on Smoking Prevalence, Cigarette Consumption, and Healthcare Costs: 1989-2008. PLoS ONE 8(2): e47145.

27. Max W, Sung H Y, Shi Y, Stark B (2015) The Cost of Smoking in California. Nicotine \& Tobacco Research 18(5):1222-9.

28. Sánchez González E, Fernández Hernández F (2019) A view for the morbidity attributable to smoking since the microeconomic. OAT Trends in Research 2: 1-2.

29. Fernández Hernández F, Sánchez González E (2017) Carga epidemiológica vs carga económica del tabaquismo por morbilidad. Rev Ciencias Médicas 21(2): 210-216.

30. Fernández Hernández F, Sánchez González E (2020) Quantitative methods to explain the smoking economic impact. International Journal of Science and Academic Research 1(1): 1-2.

31. Fernández Hernández F, Sánchez González E (2018) Algorithm to calculate the smoking economical burden in active and passive smokers. MOJ Toxicol 4(6): 373-375. 
ISSN: 2574-1241

DOI: 10.26717/BJSTR.2021.39.006302

FéFernández Hernández. Biomed J Sci \& Tech Res

(C) This work is licensed under Creative

Submission Link: https://biomedres.us/submit-manuscript.php

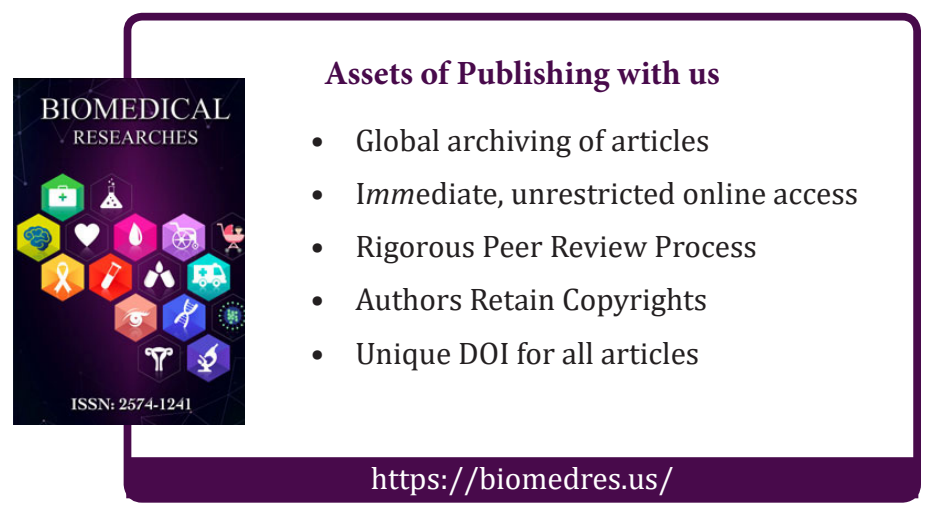

